Quantitative proteomics by 2DE and MALDI MS/MS uncover the effects of organic and conventional cropping methods on vegetable products

Nawrocki, Arkadiusz ; Thorup-Kristensen, Kristian; Jensen, Ole Nørregaard

Published in:

Journal of Proteomics

DOI:

10.1016/j.jprot.2011.06.021

Publication date:

2011

Document version

Early version, also known as pre-print

Citation for published version (APA):

Nawrocki, A., Thorup-Kristensen, K., \& Jensen, O. N. (2011). Quantitative proteomics by 2DE and MALDI MS/MS uncover the effects of organic and conventional cropping methods on vegetable products. Journal of Proteomics, 74(12), 2810-2825. https://doi.org/10.1016/j.jprot.2011.06.021 


\title{
Quantitative proteomics by 2DE and MALDI MS/MS uncover the effects of organic and conventional cropping methods on vegetable products
}

\author{
Arkadiusz Nawrocki ${ }^{a}$, Kristian Thorup-Kristensen ${ }^{b, 1}$, Ole Nørregaard Jensen ${ }^{a, *}$ \\ ${ }^{a}$ Dept. Biochemistry and Molecular Biology, University of Southern Denmark, DK-5230 Odense, Denmark \\ ${ }^{\mathrm{b}}$ Dept. Horticulture, University of Aarhus, DK-5792 Aarslev, Denmark
}

\section{A R T I C L E I N F O}

Article history:

Received 25 May 2010

Accepted 21 June 2011

Available online 2 July 2011

Keywords:

Agriculture

Metabolism

Organic farming

Mass spectrometry

Functional proteomics

\begin{abstract}
A B S T R A C T
Organic farming aims to be environmentally sound, but the question as to whether organic cropping brings more nutritional benefits to farmers and consumers than the conventional cropping needs still to be answered. To gain insights into the molecular effects of organic farming we used proteome analysis to analyze cabbage (Brassica oleracea L. var 'capitata') and carrot (Daucus carota var. 'sativus') Our aim was to identify the metabolic pathways that are affected by different cropping regimes and thus, may have an effect on quality, storability and pathogen resistance of crops. By means of two dimensional gel electrophoresis and MALDI tandem mass spectrometry we compared proteomes of cabbage and carrot root, obtained in the first growth season, cropped under three different schemes. These included a conventional scheme (C) and two organic schemes, $\mathrm{O}$, in which nutrients were delivered in a form of slurry, in accordance to regulations of organic farming and $\mathrm{O} 2$, in which nutrient supply was based mainly on autumn green manures. Proteins were extracted from lyophilized plant tissues into a buffer containing high concentrations of urea/thiourea, two detergents and reducing agent. This approach allowed short handling times of fresh plant materials. In the case of cabbage samples, the abundance levels of 58 out of more than 1300 quantified protein spots varied significantly between conventional farming and any of the organic cropping systems. Proteome profiles were also very similar between carrot root samples, where 68 out of 1800 resolved protein spots varied significantly. Proteins of the glycolytic pathway and Krebs cycle as well as several proteins related to amino acid and protein metabolism were overexpressed in organically farmed cabbage. Proteins related to detoxification processes were overexpressed in conventionally grown cabbage. Proteins involved in metabolism of carbohydrates, polypeptides and secondary metabolites were affected by different cropping regimes in carrots. The proteomes of conventionally grown vegetables varied from organically grown vegetables to a larger extent than the two organic cropping schemes varied from each other. In conclusion, this proteomics platform is suitable and useful for systematic studies of the effects of organic and conventional farming techniques on plant metabolism.
\end{abstract}

(c) 2011 Elsevier B.V. All rights reserved.

\footnotetext{
* Corresponding author at: Department of Biochemistry and Molecular Biology, University of Southern Denmark, Campusvej 55, DK-5230 Odense M, Denmark. Tel.: +45 65502368; fax: +45 65502467.

E-mail address: jenseno@bmb.sdu.dk (O.N. Jensen).

${ }^{1}$ Current address: Department of Agriculture and Ecology, University of Copenhagen.
} 


\section{Introduction}

Farming of vegetables without or with only limited use of inorganic fertilizers and pesticides is appealing to consumers and beneficial to the environment. However, the effects of organic farming methods on vegetable crop quality, resistance to pathogens, yield, storability and nutrient contents has not been systematically investigated [1]. There are many reasons as to why organically grown crops may possess a different and better quality than conventional crops, and why differences in effects on field biodiversity and other environmental effects may be expected. Inorganic fertilizers, for example, can give a strong and unbalanced nutrition of the crop. With a high nutrient availability, the crops are induced to grow at maximum rates, and thereby to use practically all of their photosynthesis products for growth. This leaves a reduced surplus for other functions of the plants, such as the production of secondary metabolites [2].

The effects of organic farming on plant physiology and product quality are highly complex and thus difficult to study. Furthermore, organic farming is not just one well defined cropping system, and within the regulations for organic farming many very different systems can be designed. For example, excessive fertilization can be used in organic farming, leading to nitrogen leaching losses and negative effects on crop quality [3]. It has been shown that efficient use of catch crops and green manure crops can supply much of the nitrogen needed by organically grown vegetables [4] and can be used as an alternative to mineral fertilization. At the same time, these fertility building crops can efficiently reduce nitrogen leaching losses and improve the living conditions for the soil biology [5].

The complex relationship between farming practices and the metabolism and physiology of crops is further illustrated by divergent results obtained after application of pesticides and subsequent contents of secondary metabolites in plants $[6,7]$. Recently, a large scale study conducted at the Nafferton Experimental Farm (University of Newcastle) addressed effects of different farming regimes on protein profiles in potato tubers using 2D electrophoresis/mass spectrometry based approach [8]. Only fertilization management practices (organic versus mineral) had a significant effect on protein profiles of potato tubers and interestingly, crop protection treatment did not cause significant differences in the proteome of tubers.

As part of an ongoing Danish study (VegQure) of organic and conventional farming practices we compare the quality and environmental consequences of different cropping systems. We measure several factors including effects on specific secondary compounds in the vegetables combined with broader analysis of taste and plant product quality.

We use proteomics to investigate the physiology and molecular phenotype of plants, viz. carrots and cabbage. 2DE based proteomic approaches are valuable primarily because they simplify the analysis of complex samples by resolving intact proteins and enzymes involved in various metabolic processes and enables characterization of protein activity by detection of protein heterogeneity, including post-translational processing events that lead to alteration of $\mathrm{pI}$ or molecular mass of proteins [9]. The 2DE technique has been successfully used in plant proteomics, for example for investigations of varieties or ploidy of plants $[10,11]$, plant development studies
$[12,13]$ or plant physiology and allergenecity [14] as well as plants defense to pathogens [15].

Carrot and cabbage are among the most frequently consumed vegetables in the world and they are rich sources of nutrients and vitamins. The plant storage organs, i.e. the carrot root and the cabbage head are exposed to very different environments below and above the ground, respectively. The genomes of these two plant varieties have not been sequenced yet, though sequencing of cabbage genome has been initiated [http://www.brassica.bbsrc.ac.uk; [16]] and the complete plastid sequence of carrot was reported [17]. Cabbage belongs to the same family of plants (Brassicaceae) as Arabidopsis thaliana, for which the complete genome is available [18], thus allowing for cross-species protein identification of cabbage proteins.

Extraction of proteins for 2DGE from plant material is more challenging than extraction from animal tissue or microorganisms, mainly due to presence of cell wall and large vacuoles. The techniques developed to extract proteins from plant material are based primarily on precipitation of proteins from crude plant extracts and subsequent suspension of precipitated proteins in buffers used for electrophoretic separation [19-22].

Tandem mass spectrometry is a key analytical technology in proteomics. Its full potential is revealed when studying organisms for which the complete genomic information and/ or all translated open reading frames are available. Proteomic analysis of organisms for which the genome is unknown or only partially sequenced is possible by using tandem mass spectrometry for de novo peptide sequencing followed by sequence homology searching of the determined amino acid sequences in protein sequence databases.

Peptides derived by tryptic digestion of 2DE protein spots can be chemically derivatized and sequenced by MALDI MS/ MS [23-25]. The determined amino acid sequence of peptides is subsequently used for sequence homology searching against protein sequence databases [26]. The MALDI MS/MS approach is sensitive and robust and a peptide sample can be analyzed several times after it has been deposited onto the MALDI MS target [14,27].

The combination of 2DE based protein separation with tandem mass spectrometry for peptide sequencing is an attractive method for characterization of organisms for which the genome is not yet available. In the present study we demonstrate that optimized protein extraction protocols in combination with 2DE for protein separation and MALDI MS/MS for de novo peptide sequencing is applicable to the analysis, identification and quantification of proteins extracted from carrot and cabbage. We then used this method to characterize the proteomes of plants grown under conventional farming conditions $(\mathrm{C})$ and two different organic farming conditions (O1-O2).

\section{Materials and methods}

\subsection{Field experiments}

The rotation experiment was initiated in the autumn of 2005 on an area grown organically since 1996 . The three cropping systems were a conventional system (C) where inorganic fertilizers, pesticides, herbicides and fungicides were used according to normal practice, an organic system (O1) where 
nutrient supply was based on import of slurry for the crops and another organic system (O2) where very little fertilizer is imported, and where the autumn and winter seasons were used for green manure crops grown to supply nitrogen for the crops. In the organic systems no inorganic fertilizers or chemical crop protection was used. In the present study cabbage heads and carrot roots were sampled and analyzed.

The sequence of main crops was identical in the three systems, thus in all systems the cabbage crop followed a rye crop in the previous year, and carrots followed an oat crop in the previous year. In the $\mathrm{C}$ system and the $\mathrm{O} 1$ system the soil was left without plant cover in the periods from harvest of the rye and oat crops until establishment of the next main crop, whereas in the $\mathrm{O} 2$ system mixtures of grass and legumes were sown into the cereal crops in the spring, left to grow in the autumn after harvest, and incorporated into the soil in early spring before establishment of the vegetables.

In the conventional system cereals and vegetable crops were all fertilized with inorganic fertilizers according to common practice, the cabbages were fertilized with $310 \mathrm{~kg} \mathrm{~N} \mathrm{ha}^{-1}$ and the carrots with $120 \mathrm{~kg} \mathrm{~N} \mathrm{ha}^{-1}$. In the $\mathrm{O} 1$ system the crops were all fertilized with slurry, quite low rates were used for the cereals and the cabbage and carrot received 250 and $60 \mathrm{~kg} \mathrm{~N}^{-1}$ respectively with the slurry. In the $\mathrm{O} 2$ the cabbage crop received $150 \mathrm{~kg} \mathrm{~N}^{-1}$ in the form of slurry, whereas the cereals and carrots did not receive any fertilizer. The slurry applied came from a facility producing biogas based mainly on slurry from conventional pig production. The slurry contained $3.4 \%$ dry matter, and of the main plant nutrients it contained $0.56 \% \mathrm{~N}(0.42 \%$ of which as ammonium N, 0.05\% P and 0.19\% K). Pesticides, herbicides, and fungicides were applied according to normal Danish practice in the $\mathrm{C}$ system, but they were not applied in the $\mathrm{O} 1$ and $\mathrm{O} 2$ systems.

At harvest in October the total yield of edible product of carrot and cabbage were determined from c. $10 \mathrm{~m}^{2}$ subplots in each field plot. Subsamples of the harvested products were oven dried $\left(80^{\circ} \mathrm{C}\right.$ for $24 \mathrm{~h}$ ) to determine dry weight and obtain dry samples for analysis of nutrient contents. Nitrogen content was determined by the Dumas combustion method.

\subsection{Crop sample collection}

In order to shorten the time from the harvest to freezing down of the collected plant material, plants were harvested and frozen from one experimental plot at a time. From each of the experimental plots ten representative plants of cabbage or carrot were selected which grew at least $1 \mathrm{~m}$ away from the field edge. Plants were pulled out of soil and immediately transported to the laboratory.

Samples of cabbage (Brassica oleracea var. 'capitata') for protein extraction were prepared by removing the loose outer leaves and the cabbage head was then cut vertically into quarters. From the middle of one of the quarter heads a $1 \mathrm{~cm}$ thick slice was cut out horizontally. This slice was cut in halves from the stem to the outer leaves and one of the halves was frozen in liquid nitrogen. Thus, the sample taken encompassed stem, inner leaves and outer leaves in the correct proportion. Frozen plant material was freeze dried and ground to a fine powder in an electric mill (Ultra Centrifugal Mill, ZM1, Retsch).

Samples of carrot (Daucus carota var. 'sativa') for protein extraction were prepared by washing the carrot roots briefly of soil and cutting a single $1 \mathrm{~cm}$ thick slice out from the middle of the root. The selected plant material from the ten plants from each field plot was combined to one sample, frozen in liquid nitrogen, freeze dried, and finally ground to a fine powder in an electric mill (as above).

For both vegetables under study, each cropping condition was carried out on three separated field plots. Samples from each of the field plots were processed and analyzed using 2D gels, thus generating three 2D gels (triplicates) for each cropping condition.

\subsection{Extraction of proteins for 2D gel analysis}

Two approaches were applied to extract proteins from the plant material. In the 1st approach proteins were extracted to an extraction buffer, precipitated, and resuspended in the extraction buffer suitable for subsequent 2DGE analysis. Briefly, $6 \mathrm{ml}$ of extraction buffer was added to $200 \mathrm{mg}$ of the plant powder, and proteins were extracted for $7 \mathrm{~h}$ in $15 \mathrm{ml}$ Falcon tubes with vigorous mixing at room temperature. The extraction buffer consisted of $7 \mathrm{M}$ urea, $2 \mathrm{M}$ thiourea, 2\% CHAPS, $2 \%$ Igepal and $0.4 \%$ DTT. Protein extracts were centrifuged for $15 \mathrm{~min}$ at $20,000 \times \mathrm{g}$. Proteins were precipitated from $1 \mathrm{ml}$ of the supernatant obtained by mixing it with 4 volumes of cold ethanol followed by addition of 4 volumes of cold acetone. Proteins were precipitated overnight at $-20^{\circ} \mathrm{C}$. Precipitated proteins were centrifuged down for $20 \mathrm{~min}$ at $20,000 \times g$. Protein pellets were resuspended in ethanol:acetone:water $\operatorname{mix}(2: 2: 1)$ and placed at $-20^{\circ} \mathrm{C}$ for $90 \mathrm{~min}$, followed by centrifugation for $15 \mathrm{~min}$ at $20,000 \times \mathrm{g}$. This washing was repeated 3 times. Washed protein pellets were dried in a speedvac for $20 \mathrm{~min}$ and resuspended in an extracting buffer supplemented with $0.5 \%$ (w/w) Pharmolyte 3-10 and 0.5\% (w/w) IPG Buffer 6-11 (GE Healthcare).

In the 2nd approach plant material was suspended in TCA/ beta-mercaptoethanol/acetone mix followed by centrifugation and several washes of the pellet and finally, extraction of proteins from dried pellet to an extraction buffer, principally as described in [20]. $80 \mathrm{mg}$ of the powder was suspended in $3.8 \mathrm{ml}$ of freshly prepared solution of $10 \%$ TCA, $0.07 \%$ betamercaptoethanol in acetone. The suspension was placed in $-20^{\circ} \mathrm{C}$ for $1 \mathrm{~h}$. Samples were centrifuged for $15 \mathrm{~min}$ at $20,000 \times g$ at $4{ }^{\circ} \mathrm{C}$. The collected pellet was washed of TCA by resuspension in $3.8 \mathrm{ml}$ of freshly prepared solution of $0.07 \%$ beta-mercaptoethanol in acetone and placed in $-20^{\circ} \mathrm{C}$ for $1 \mathrm{~h}$. The suspension was centrifuged as above. The washing step was repeated three times. The collected pellet after the last washing was dried in speedvac for $20 \mathrm{~min}$ and proteins were extracted overnight to a buffer composed of $7 \mathrm{M}$ urea, $2 \mathrm{M}$ thiourea, 2\% CHAPS, 2\% Igepal, 0.4\% DTT, 0.5\% Pharmolyte 3-10 and $0.5 \%$ IPG Buffer 6-11. Protein concentration was estimated using Bradford reagent (BioRad) against a standard curve based on BSA (BioRad) prepared in the extraction buffer.

\subsection{D gel electrophoresis and image analysis}

Gel electrophoresis was performed as described elsewhere [28] with some modifications. The IEF of proteins proceeded in IPG 4 7 gels for 63,000 Vhrs on a Multiphore II unit (GE Healthcare). SDSPAGE was performed using homemade $15 \%$ polyacrylamide gels 
Table 1 - Variation in spots intensity in the triplicates. The $\%$ volume of the protein spots for each field triplicates was averaged and the standard deviation was calculated. The standard deviation was then expressed as a percent of the average (\%STDEV). For each of the field triplicates, the average of the \%STDEV for all of the 1380 (cabbage) and 1829 (carrot root) matched spots was calculated.

\begin{tabular}{lccc} 
Vegetable & \multicolumn{3}{c}{ Cropping system } \\
\cline { 2 - 4 } & Conventional & Organic I & Organic II \\
\hline Cabbage & 26.1 & 25.3 & 27.2 \\
Carrot Root & 32.2 & 28.8 & 28.7 \\
\hline
\end{tabular}

(200:1 acrylamide:bisacrylamide) (BioRad). The highest protein density for both cabbage and carrot root was observed at around $40 \mathrm{kDa}$ molecular weight. The lowest $2-3 \mathrm{~cm}$ of the 2D gels showed few protein spots and we decided to sacrifice the few lightest proteins for better separation of heavier ones. Therefore, after bromophenol blue reached the bottom edge of the second dimension gel, the current was set to $20 \mathrm{~mA}$ per gel and proteins were separated for additional $1 \mathrm{~h}$. Proteins were fixed for a minimum of $1 \mathrm{~h}$ in $45 \%$ methanol, $7.5 \%$ acetic acid in deionized water and stained for $3 \mathrm{~h}$ in SyproRuby® (Molecular Probes/ Invitrogen). Proteins were visualized using a Typhoon scanner (GE Healthcare). Gel images were analyzed using Image Master ${ }^{\mathrm{TM}}$ 2D Platinum software v.5.0 (GE Healthcare). The normalization of spot intensity was done by expressing the volume of each of the detected spot in a gel as a fraction of the total spot volume for that gel (\%Vol). The normalized \% spot volumes (\%Vols) of corresponding protein spots in triplicates of each experiment were averaged and the standard deviation was calculated. The significance of the differences between averaged spot volumes between any of the organic cropping conditions and the conventional system was tested using Student's t-test, with $p \leq 0.05$. In order to test for the quantitative reproducibility in spot $\%$ Vols within any of the cropping systems, the standard deviation of the \%Vols was expressed as a percentage of their average \%Vl and then averaged across triplicate experiments (\% standard deviation).

\subsection{MS identification of proteins}

Protein spots whose intensity differed significantly between conventionally grown and any of the organically cropped vegetables were excised from the gels and digested with trypsin as described elsewhere $[14,29,30]$. The sequencing of selected peptides was improved by chemical derivatization of peptides by SPITC prior to MS/MS as reported [23,25], but with minor modifications. 4-Sulfophenyl isothiocyanate sodium salt monohydrate reagent (SPITC, SIGMA-Aldrich) was dissolved in $50 \mathrm{mM}$ $\mathrm{NaHCO}_{3}$ (pH 8.6) to a concentration of $10 \mu \mathrm{g} / \mu \mathrm{l}$. $8.5 \mu \mathrm{l}$ of the reagent solution was mixed with a few picomoles of digested

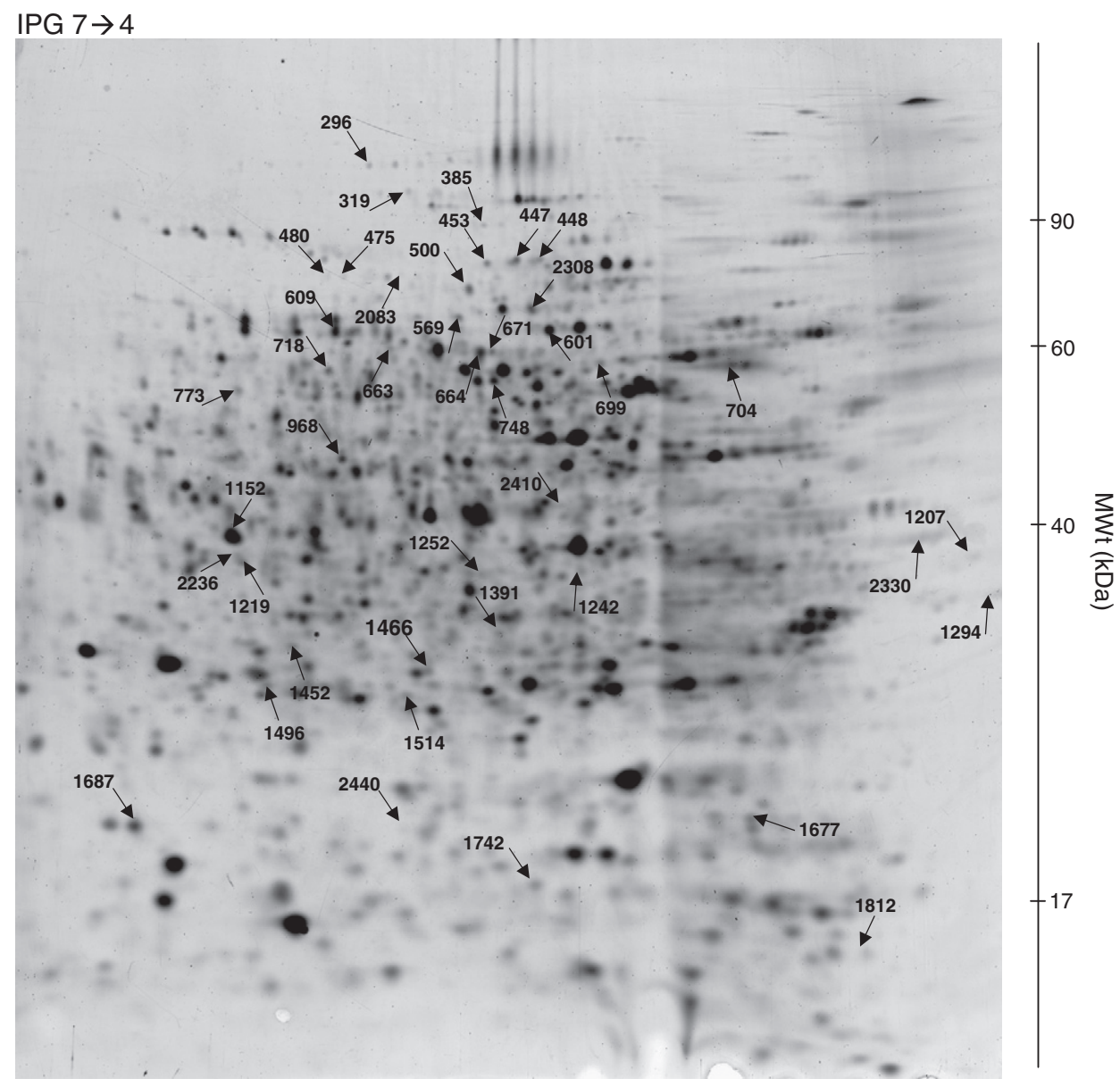

Fig. 1 - Image of the reference gel of cabbage samples. The numbers in the gel image refer to protein-spot numbers in Fig. 2 and Table 2. 
protein and incubated at $50{ }^{\circ} \mathrm{C}$ for $30 \mathrm{~min}$. Derivatization was stopped by addition of $1 \mu \mathrm{l}$ of $5 \%$ TFA. Peptides were purified using homemade reverse phase micro-columns (POROS 20 R2, PerSeptive Biosystems) [31] and released from the columns directly onto a MALDI MS target with $5 \mathrm{mg} / \mathrm{ml}$ solution of $\alpha$-Cyano-4-hydroxycinnamic acid in 70\% acetonitrile/0.1\% TFA. Proteins were identified using a 4800 Plus MALDI TOF/TOF Analyser (Applied Biosystems/MDS SCIEX). MS/MS data were searched against public databases (NCBI and SwissProt) using Mascot (Matrix Science) and MS BLAST Search (BLASTP2) at EMBL against nrdb95 database [26]. Unless otherwise stated, data on protein function was obtained from the Swiss-Prot database (www.expasy.ch) and available scientific resources linked to particular protein entries therein.

\section{Results}

We report results of proteome analysis of cabbage and carrot roots grown in three different cropping systems as described in Materials and methods. The systems were a conventional system (C) relying on inorganic fertilizers and chemicals for crop protection, an organic system (O1) based on import of slurry for nutrient supply, and another organic system (O2) based mainly on green manures grown during the autumn and winter seasons to supply nitrogen for the main crops.

The total yields of cabbages were 87,68 , and $73 \mathrm{Mg} \mathrm{ha}^{-1}$ in the $\mathrm{C}, \mathrm{O} 1$, and $\mathrm{O} 2$ systems respectively, whereas in carrots the yields were 95,85 , and $90 \mathrm{Mg} \mathrm{ha}^{-1}$. In cabbages $\mathrm{N}$ concentrations in the harvested product were unaffected by the cropping system (all close to $2.1 \% \mathrm{~N}$ in dry matter), whereas in carrots it was slightly lower in the organic than in the conventional system (0.95 in C vs 0.79 and 0.90 in 01 and O2). Crop dry matter percentage was not affected by the cropping systems. All in all, the plant development and $\mathrm{N}$ uptake of cabbages and carrots were comparable among the three systems, and affected less by organic cropping than often seen in experiments.

Vegetables were freeze dried and ground up and proteins were extracted for subsequent 2DE analysis. There are a number of methods to precipitate proteins in a manner that the proteins can then be dissolved in an appropriate buffer and separated using 2DE. We looked for a robust method which could be applied to plant material and be applicable to a number of samples simultaneously. We initially tested two different approaches (see Materials and methods for details) that resulted in good quality separation and focusing of proteins (Supplementary data, Fig. 1). To compare these extraction methods in regard to the yields of extracted proteins, proteins from dried carrot roots and cabbage samples (from two random cropping regimes, i.e. in duplicate for each plant) were extracted. Using TCA/betamercaptethanol/ acetone extraction method we obtained 0.82 and $0.86 \mathrm{mg}$ proteins starting with $100 \mathrm{mg}$ lyophilized and grinded carrot root samples. For cabbage, from $100 \mathrm{mg}$ of dried plant powder, we obtained 1.4 and $1.36 \mathrm{mg}$ proteins using this extraction method. Higher yields of proteins, extracted from the same amounts of starting plant material, were obtained using acetone/ ethanol protein extraction protocol. They were 3.1 and $3.25 \mathrm{mg}$ proteins for carrot root and 2.8 and $2.6 \mathrm{mg}$ of proteins from cabbage.

In the VegQure project we investigate also the interactions between pathogenic fungi and carrot root using 2DE techniques (S. Louarn, et al., manuscript in preparation). In our hands, the

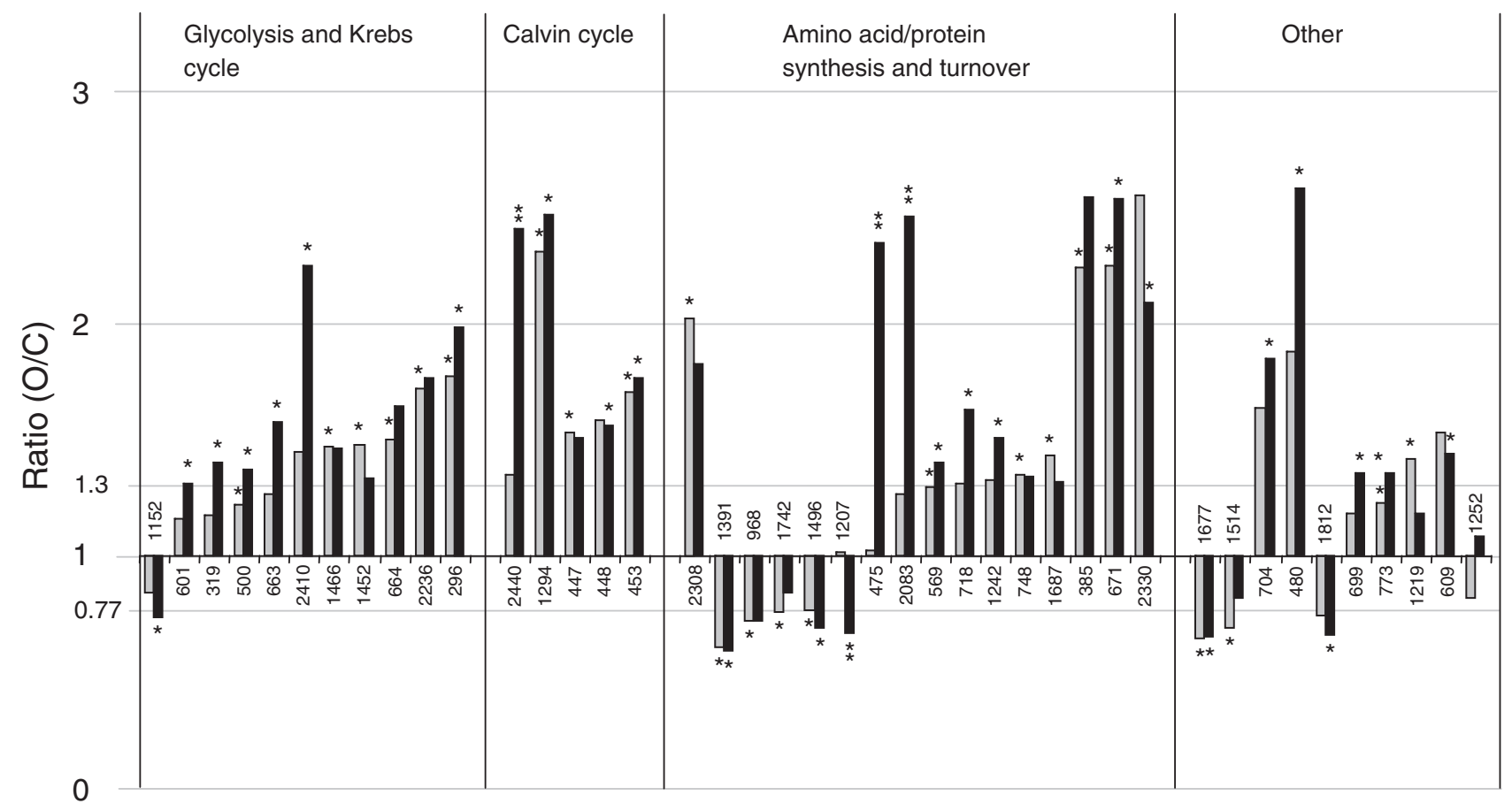

Fig. 2 - Intensity ratios for the identified proteins from differently cropped cabbages. Ratio of spot \% volume of O1 vs C (gray bars) and 02 vs $\mathrm{C}$ (black bars). Asterisk over a bar indicates that the ratio is at probability level of $\mathrm{p}=0.05$ or less. Bars annotated with two asterisks indicate that the ratio obtained for $02 \mathrm{vs} 01$ is significant. Numbers above or beneath a pair of bars refer to position of a protein-spot in Fig. 1 and Table 2. For spot \#1252 only the ratio 02/01 is significant. 


\begin{tabular}{|c|c|c|c|c|c|c|c|c|c|c|c|c|}
\hline \multirow{2}{*}{$\begin{array}{l}\text { Protein } \\
\text { spot \# }\end{array}$} & \multirow[t]{2}{*}{ Acc. $\#^{\mathrm{b}}$} & \multirow[t]{2}{*}{ Protein name ${ }^{c}$} & \multirow{2}{*}{$\begin{array}{c}\text { Best } \\
\text { match to }\end{array}$} & \multicolumn{2}{|r|}{$\mathrm{O} 1 / \mathrm{C}$} & \multicolumn{2}{|r|}{ O2/C } & \multicolumn{2}{|r|}{$\mathrm{O} 2 / \mathrm{O} 1$} & \multirow[t]{2}{*}{$\mathrm{m} / \mathrm{z}^{\mathrm{e}}$} & \multirow[t]{2}{*}{ Score ${ }^{f}$} & \multirow[t]{2}{*}{ Sequence $^{\mathrm{g}}$} \\
\hline & & & & Ratio & $\begin{array}{l}\text { Probability } \\
\text { (p) }\end{array}$ & Ratio & $\begin{array}{l}\text { Probability } \\
\text { (p) }\end{array}$ & Ratio & $\begin{array}{l}\text { Probability } \\
\text { (p) }\end{array}$ & & & \\
\hline \multicolumn{13}{|c|}{ Glycolysis and Krebs cycle } \\
\hline \multirow[t]{4}{*}{1152} & P25858 & Glyceraldehyde-3-phosphate & A.th. & 0.84 & & 0.73 & 0.0074 & 0.87 & & 1498.89 & 132 & VPTVDVSVVDLTVR \\
\hline & & dehydrogenase, cytosolic & & & & & & & & 1677.02 & 110 & TLLFGEKPVTVFGIR \\
\hline & & & & & & & & & & 1750.85 & 98 & DAPMFVVGVNEHEYK (Mox) \\
\hline & & & & & & & & & & 2172.07 & 186 & GILGYTEDDVVSTDFVGDNR \\
\hline \multirow{5}{*}{601} & gi|15239146 & NADP-dependent malic enzyme & A.th. & 1.16 & & 1.31 & 0.0172 & 1.13 & & 742.39 & 20 & YGSIFR \\
\hline & & & & & & & & & & 1004.55 & 27 & QYTVPLQR \\
\hline & & & & & & & & & & 1285.70 & 67 & GIQVIVVTDGER \\
\hline & & & & & & & & & & 1389.76 & 91 & KPQGLYISLNEK \\
\hline & & & & & & & & & & 2364.24 & 55 & DAHYLTGLLPPVILSQDVQER \\
\hline \multirow[t]{2}{*}{319} & Q42560 & Aconitate hydratase 1 , cytosolic & C.ma. & 1.17 & & 1.40 & 0.0056 & 1.19 & & 1184.66 & 20 & QVEIPFKPAR \\
\hline & & & & & & & & & & 1529.68 & 27 & SDETVSMIEAYLR (Mox) \\
\hline \multirow[t]{4}{*}{500} & Q6ZDY8 & Succinate dehydrogenase [ubiquinone] & O.sa & 1.22 & 0.0252 & 1.37 & 0.0001 & 1.12 & & 1126.55 & 65 & AFGGQSLDFGK \\
\hline & & flavoprotein subunit, mitochondrial & & & & & & & & 1294.67 & 48 & ATNTILATGGYGR \\
\hline & & & & & & & & & & 1473.84 & 114 & LGANSLLDIVVFGR \\
\hline & & & & & & & & & & 1607.84 & 72 & AVIELENYGLPFSR \\
\hline \multirow[t]{4}{*}{663} & gi|34597330 & Enolase & B.ra. & 1.27 & & 1.58 & 0.0141 & 1.24 & & 1573.83 & 37 & VNQIGSVTESIEAVK \\
\hline & & & & & & & & & & 1854.88 & 67 & IEEELGSEAVYAGANFR \\
\hline & & & & & & & & & & 2005.06 & 54 & VTAAVPSGASTGIYEALELR \\
\hline & & & & & & & & & & 2268.11 & 106 & SGETEDTFIADLSVGLSTGQIK \\
\hline \multirow[t]{4}{*}{2410} & P50318 & Phosphoglycerate kinase, chloroplast & A.th. & 1.44 & & 2.25 & 0.0132 & 1.56 & & 1388.73 & 63 & ELDYLVGAVANPK \\
\hline & & & & & & & & & & 1749.02 & 50 & LVAGLPEGGVLLLENVR \\
\hline & & & & & & & & & & 2015.95 & 95 & VDLNVPLDDNSNITDDTR \\
\hline & & & & & & & & & & 2370.28 & 50 & GVSLLLPTDVVIADKFAPDANSK \\
\hline \multirow[t]{3}{*}{1466} & P48491 & Triosephosphate isomerase, cytosolic & A.th. & 1.47 & 0.0023 & 1.46 & & 0.99 & & 1649.85 & 50 & VASPAQAQEVHDELR \\
\hline & & & & & & & & & & 1777.95 & 48 & VASPAQAQEVHDELRK \\
\hline & & & & & & & & & & 2788.56 & 109 & ELGGQADVDGFLVGGASLKPEFIDIIK \\
\hline \multirow[t]{3}{*}{1452} & P48491 & Triosephosphate isomerase, cytosolic & A.th. & 1.48 & 0.0070 & 1.33 & & 0.90 & & 1649.91 & 22 & VASPAQAQEVHDELR \\
\hline & & & & & & & & & & 1778.01 & 66 & VASPAQAQEVHDELRK \\
\hline & & & & & & & & & & 2788.64 & 125 & ELGGQADVDGFLVGGASLKPEFIDIIK \\
\hline 664 & gi|34597330 & Enolase & B.ra. & 1.50 & 0.0477 & 1.64 & & 1.09 & & 1573.83 & 115 & VNQIGSVTESIEAVK \\
\hline & & & & & & & & & & 1854.88 & 118 & IEEELGSEAVYAGANFR \\
\hline & & & & & & & & & & 2005.05 & 96 & VTAAVPSGASTGIYEALELR \\
\hline 2236 & gi|207667274 & Malate dehydrogenase, chloroplastic & A.th. & 1.72 & 0.0048 & 1.76 & & 1.03 & & 1219.70 & 60 & LFGVTTLDVVR \\
\hline & & & & & & & & & & 1318.69 & 104 & DDLFNINAGIVK \\
\hline & & & & & & & & & & 1347.80 & 82 & KLFGVTTLDVVR \\
\hline & & & & & & & & & & 1484.71 & 31 & AGAGSATLSMAYAAAR (Mox) \\
\hline & & & & & & & & & & 1777.10 & 135 & VAVLGAAGGIGQPLSLLIK \\
\hline 296 & Q9SIB9 & Aconitate hydratase 2 & A.th. & 1.77 & 0.0378 & 1.98 & 0.0427 & 1.12 & & 1184.67 & 35 & QVEIPFKPAR \\
\hline & & & & & & & & & & 1292.66 & 42 & FYSLPALNDPR \\
\hline & & & & & & & & & & 1513.71 & 27 & SDETVAMIEAYLR (Mox) \\
\hline & & & & & & & & & & 1605.85 & 34 & GIFTTLPKPGGGEFGK \\
\hline Calvin cy & & & & & & & & & & & & \\
\hline 2440 & 003042 & Ribulose bisphosphate carboxylase large & A.th. & 1.35 & & 2.40 & 0.0136 & 1.78 & 0.0130 & 1249.68 & 42 & ESTLGFVDLLR \\
\hline & & chain (truncated) & & & & & & & & 1819.94 & 17 & LEGDRESTLGFVDLLR \\
\hline
\end{tabular}




\section{Table 2 (continued)}

Protein Acc. $\#^{\text {b }}$

spot \# ${ }^{\mathrm{a}}$

Protein name

Best

O1/C

O2/C

02/O1

-

$\mathrm{m} / \mathrm{z}^{\mathrm{e}} \quad$ Score $^{\mathrm{f}}$

Sequence $^{g}$

\begin{tabular}{|c|c|c|c|c|c|c|c|c|c|c|c|c|}
\hline \multicolumn{13}{|c|}{ Calvin cycle } \\
\hline \multirow[t]{3}{*}{1294} & 003042 & Ribulose bisphosphate carboxylase large & A.th. & 2.31 & 0.0086 & 2.46 & 0.0473 & 1.07 & & 2185.97 & 44 & GGLDFTKDDENVNSQPFMR (Mox) \\
\hline & & chain (truncated) & & & & & & & & 1819.94 & 70 & LEGDRESTLGFVDLLR \\
\hline & & & & & & & & & & & 42 & \\
\hline \multirow[t]{3}{*}{447} & gi|7329685 & Transketolase-like protein & A.th. & 1.53 & 0.0329 & 1.51 & & 0.99 & & 1575.78 & 84 & ALPTYTPESPGDATR \\
\hline & & & & & & & & & & 1806.00 & 108 & SIGINSFGASAPAPLLYK \\
\hline & & & & & & & & & & 2093.13 & 109 & VVPGFLGGSADLASSNMTLLK (Mox) \\
\hline \multirow[t]{3}{*}{448} & gi|7329685 & Transketolase-like protein & A.th. & 1.58 & & 1.56 & 0.0243 & 0.99 & & 1005.56 & 44 & FLAIDAVEK \\
\hline & & & & & & & & & & 1575.75 & 37 & ALPTYTPESPGDATR \\
\hline & & & & & & & & & & 2093.08 & 38 & VVPGFLGGSADLASSNMTLLK (Mox) \\
\hline \multirow[t]{2}{*}{453} & gi|7329685 & Transketolase-like protein (truncated) & A.th. & 1.70 & 0.0057 & 1.76 & 0.0176 & 1.04 & & 1448.77 & 44 & EFGITVEAVVDAAK \\
\hline & & & & & & & & & & 1806.01 & 24 & SIGINSFGASAPAPLLYK \\
\hline \multicolumn{13}{|c|}{ Amino acid/protein synthesis and turnover } \\
\hline 2308 & 004130 & $\begin{array}{l}\text { D-3-phosphoglycerate dehydrogenase, } \\
\text { chloroplast }\end{array}$ & A.th. & 2.02 & 0.0037 & 1.82 & & 0.90 & & 1717.95 & 69 & IGEIPAIEEFVFLKL \\
\hline 1391 & O50008 & $\begin{array}{l}\text { 5-methyltetrahydropteroyltriglutamate- } \\
\text { homocysteine methyltransferase } \\
\text { (truncated) }\end{array}$ & A.th. & 0.61 & 0.0012 & 0.60 & 0.0056 & 0.98 & & 1132.65 & 66 & SFDLLSLLPK \\
\hline \multirow[t]{4}{*}{968} & 050008 & 5-methyltetrahydropteroyltriglutamate- & A.th. & 0.73 & 0.0386 & 0.72 & & 0.99 & & 1096.60 & 71 & YLFAGVVDGR \\
\hline & & homocysteine methyltransferase & & & & & & & & 1181.65 & 74 & GVTAFGFDLVR \\
\hline & & (truncated) & & & & & & & & 2015.00 & 66 & YGYTGGEIGLDVYFSMAR (Mox) \\
\hline & & & & & & & & & & 2075.17 & 180 & ALAGQKDEALFSANAAALASR \\
\hline 1742 & Q9SRC3 & ADP-ribosylation factor 2 (truncated) & A.th. & 0.76 & 0.0177 & 0.84 & & 1.11 & & 2323.27 & 69 & LGEIVTTIPTIGFNVETVEYK \\
\hline \multirow[t]{2}{*}{1496} & 050008 & 5-methyltetrahydropteroyltriglutamate- & A.th. & 0.77 & 0.0348 & 0.69 & 0.0320 & 0.90 & & 1411.78 & 49 & GGIGVIQIDEAALR \\
\hline & & $\begin{array}{l}\text { homocysteine methyltransferase } \\
\text { (C-terminus) }\end{array}$ & & & & & & & & $+\mathrm{PMF}$ & & 10 matching peptides, $9 \%$ sequence coverage \\
\hline \multirow[t]{3}{*}{1207} & Q6ICZ8 & Nascent polypeptide-associated complex & A.th. & 1.02 & & 0.67 & 0.0256 & 0.66 & 0.0474 & 1174.65 & 16 & LGMKPITGVSR (Mox) \\
\hline & & subunit alpha-like protein 3 & & & & & & & & 1484.72 & 123 & SPASDTYVIFGEAK \\
\hline & & & & & & & & & & 1921.94 & 132 & IEDLSSQLQSQAAEQFK \\
\hline \multirow[t]{3}{*}{475} & 050008 & 5-methyltetrahydropteroyltriglutamate- & A.th. & 1.02 & & 2.34 & 0.0070 & 2.29 & 0.0010 & 1096.57 & 54 & YLFAGVVDGR \\
\hline & & homocysteine methyltransferase & & & & & & & & 1181.63 & 63 & GVTAFGFDLVR \\
\hline & & (truncated) & & & & & & & & 2075.08 & 168 & ALAGQKDEALFSANAAALASR \\
\hline 2083 & Q9LNU4 & $\begin{array}{l}\text { Probable } 26 \mathrm{~S} \text { proteasome non-ATPase } \\
\text { regulatory subunit } 3 a\end{array}$ & A.th. & 1.27 & & 2.46 & 0.0006 & 1.94 & 0.0045 & PMF & 61 & 6 matching peptides, $14 \%$ seq. coverage \\
\hline 569 & gi|22331076 & Subtilisin-like protease (truncated) & A.th. & 1.30 & 0.0379 & 1.40 & 0.0007 & 1.08 & & 1549.79 & 115 & NVGSNVDAVYEVGVK \\
\hline \multirow[t]{5}{*}{718} & P31542 & ATP-dependent Clp protease ATP-binding & S.ly. & 1.31 & & 1.63 & 0.0186 & 1.24 & & 1158.63 & 21 & VLELSLEEAR \\
\hline & & subunit clpA homolog $\mathrm{CD} 4 \mathrm{~B}$, chloroplast & & & & & & & & 1397.73 & 65 & VLENLGADPSNIR \\
\hline & & (truncated) & & & & & & & & 1476.78 & 62 & GSGFVAVEIPFTPR \\
\hline & & & & & & & & & & 1759.91 & 77 & FLPDKAIDLIDEAGSR \\
\hline & & & & & & & & & & 2181.20 & 54 & FQPVKVPEPTVDETIQILK \\
\hline \multirow[t]{2}{*}{1242} & P29102 & 3-isopropylmalate dehydrogenase, & B.na. & 1.32 & & 1.50 & 0.0081 & 1.14 & & 1308.69 & 49 & ELTGGIYFGVPR \\
\hline & & chloroplast & & & & & & & & 1332.67 & 25 & EVAEGVDLMVVR (Mox) \\
\hline 748 & gi|21487 & Leucine aminopeptidase & S.tu. & 1.34 & 0.0421 & 1.34 & & 1.00 & & 1271.64 & 75 & GLTFDSGGYNLK \\
\hline 1687 & Q9SRC3 & ADP-ribosylation factor 2 & A.th. & 1.43 & 0.0151 & 1.32 & & 0.92 & & 1089.65 & 66 & DAVLLVFANK \\
\hline \multirow[t]{3}{*}{385} & P46523 & ATP-dependent Clp protease ATP-binding & B.na. & 2.24 & 0.0180 & 2.54 & & 1.13 & & 1397.74 & 37 & VLENLGADPSNIR \\
\hline & & subunit clpA homolog, chloroplast & & & & & & & & 1476.79 & 29 & GSGFVAVEIPFTPR \\
\hline & & & & & & & & & & 1574.86 & 25 & EIADILLKEVFER \\
\hline
\end{tabular}




\begin{tabular}{|c|c|c|c|c|c|c|c|c|c|c|c|c|}
\hline 671 & P50246 & Adenosylhomocysteinase & M.sa. & 2.24 & 0.0190 & 2.53 & 0.0375 & 1.13 & & $\begin{array}{l}1014.60 \\
1421.72\end{array}$ & $\begin{array}{l}35 \\
41\end{array}$ & $\begin{array}{l}\text { SGIIVLAEGR } \\
\text { TEFGPSQPFKGAR }\end{array}$ \\
\hline $\begin{array}{l}2330 \\
\text { Other }\end{array}$ & P13905 & Elongation factor 1-alpha & A.th. & 2.54 & & 2.08 & 0.0023 & 0.82 & & 1025.61 & 34 & IGGIGTVPVGR \\
\hline \multirow{3}{*}{1677} & Q9SYT0 & Annexin D1 A.th. (truncated) & A.th. & 0.65 & 0.0082 & 0.65 & 0.0138 & 1.00 & & 1034.53 & 31 & AQINATFNR \\
\hline & & & & & & & & & & 1249.66 & 38 & SKAQINATFNR \\
\hline & & & & & & & & & & 1835.89 & 37 & SLEEGDDDDKFLALLR \\
\hline \multirow[t]{2}{*}{1514} & gi|121483748 & Glutathione S-transferase ERD13 & A.th. & 0.69 & 0.0102 & 0.82 & & 1.18 & & 1233.65 & 23 & YRSQGPDLLGK \\
\hline & & & & & & & & & & 1544.84 & 84 & LSAVLDVYEAHLSK \\
\hline \multirow[t]{7}{*}{704} & P24636 & Tubulin beta- 4 chain & A.th. & 1.63 & & 1.85 & 0.0028 & 1.13 & & 1027.56 & 56 & YLTASAVFR \\
\hline & & & & & & & & & & 1139.69 & 53 & LAVNLIPFPR \\
\hline & & & & & & & & & & 1231.57 & 30 & VSEQFTAMFR (Mox) \\
\hline & & & & & & & & & & 1267.78 & 50 & KLAVNLIPFPR \\
\hline & & & & & & & & & & 1274.69 & 25 & FPGQLNSDLRK \\
\hline & & & & & & & & & & 1299.61 & 72 & IDVYFNEASGGK \\
\hline & & & & & & & & & & 1679.78 & 21 & AVLMDLEPGTMDSLR (2 Mox) \\
\hline \multirow[t]{3}{*}{480} & Q09WE7 & UDP-sugar pyrophosphorylase & G.ma. & 1.88 & & 2.57 & 0.0003 & 1.37 & & 1283.68 & 41 & QYHVNSLAVPR \\
\hline & & & & & & & & & & 1387.79 & 55 & KAAFVLVAGGLGER \\
\hline & & & & & & & & & & 1903.98 & 19 & SMVINVEYNQLDPLLR \\
\hline 1812 & P32887 & Acyl carrier protein, chloroplast & B.na. & 0.75 & & 0.66 & 0.0186 & 0.89 & & 2111.21 & 77 & IATVEEAAELIEELVLLKK \\
\hline \multirow[t]{2}{*}{699} & $\mathrm{O} 23264$ & Putative selenium-binding protein & A.th. & 1.18 & & 1.35 & 0.0391 & 1.15 & & 1217.72 & 42 & YLVLPSLISGR \\
\hline & & & & & & & & & & 1515.78 & 41 & GGPQMIQLSLDGKR (Mox) \\
\hline 773 & NP_194699 & $\begin{array}{l}\text { Type I phosphodiesterase/nucleotide } \\
\text { pyrophosphatase family protein }\end{array}$ & A.th. & 1.23 & 0.0130 & 1.35 & 0.0028 & 1.10 & & 1353.67 & 63 & FTDPVTGEVFNK \\
\hline \multirow[t]{4}{*}{1219} & Q9XEE2 & Annexin D2 & A.th. & 1.41 & 0.0285 & 1.18 & & 0.84 & & 1035.67 & 53 & LIISILAHR \\
\hline & & & & & & & & & & 1158.74 & 62 & LLLPLVSTFR \\
\hline & & & & & & & & & & 1286.83 & 38 & KLLLPLVSTFR \\
\hline & & & & & & & & & & 1409.71 & 96 & ALDKELSSDFER \\
\hline \multirow[t]{2}{*}{609} & Q00326 & Myrosinase & B.ra. & 1.53 & & 1.44 & 0.0436 & 0.94 & & 1314.61 & 27 & GIYYVMDYFK (Mox) \\
\hline & & & & & & & & & & 2263.16 & 16 & NFGKDFIFGVASSAYQIEGGR \\
\hline \multirow[t]{2}{*}{1252} & Q00326 & Myrosinase (fragment) & B.na. & 0.82 & & 1.09 & & 1.32 & 0.0346 & 1023.50 & 17 & GRYPDIMR (Mox) \\
\hline & & & & & & & & & & 1314.62 & 48 & GIYYVMDYFK (Mox) \\
\hline \multicolumn{13}{|c|}{$\begin{array}{l}\text { Ratios between average \% volumes of } \mathrm{O} 1 \text { vs C, } \mathrm{O} 2 \text { vs C and } \mathrm{O} 2 \text { vs } \mathrm{O} 1 \text { for all selected } \\
\text { equal or below } 0.05 \text {. All the identified peptides were " } 1+\text { " charged. Sequences obta } \\
\text { a Protein spot \# as in Figs. } 1 \text { and } 2 \text {. } \\
\text { b Acc \# - protein accession number derived from either SwissProt or NCBI nonrec } \\
\text { c Protein name derived from either SwissProt or NCBI nonredundant databases. } \\
\text { d An organism is presented, protein of which is the best mach for the deduced (by } \\
\text { Arabidopsis thaliana; C.ma. - Cucurbita maxima; O.sa. - Oryza sativa; B.ra. - Brassica } \\
\text { Glycine max. } \\
\text { e m/z mass over charge value. Additionally, in the few instances PMF (Peptide Ma } \\
\text { f Score: mascot score is presented for the identified peptides by MSMS at } p<0.05 \text {. }\end{array}$} \\
\hline
\end{tabular}


protein extraction method using ethanol/acetone precipitation was generally applicable for protein sample preparation from various vegetables, carrot root infected with pathogenic fungus as well as from pure cultures of the fungus. Thus, for the sake of consistency in the VegQure project, samples for 2DE were prepared using ethanol/acetone precipitation.

\subsection{Expression analysis of proteins extracted from the vegetables}

\subsubsection{Cabbage heads}

The extracted proteins were separated in IPG4-7 gels and 15\% SDS-PAGE as described. Over 1300 proteins spots were detected and quantified in each of the gels. The values of the $\%$ standard deviations are presented in Table 1 . These values are relatively low, approximately $30 \%$ and thus differences in \%Vol of 1.30 and more (or 0.77 and less) show biological differences which are statistically significant with a probability $\mathrm{p} \leq 0.05$.

\subsubsection{Carrot root}

Over 1800 protein spots could be matched and quantified across all the nine gels. Similar quantitative reproducibility of separated proteins was maintained for carrot samples as for cabbage samples (Table 1).

\subsection{Protein expression differences between the vegetable cropping systems}

After manual validation of the quality of protein spot detection and matching, and the statistical analysis, 58 and 68 proteins spots were differentially expressed between the conventional and any of the organic cropping systems for cabbage and carrots, respectively. In general, the protein patterns were very similar between the samples within the triplicates but also between the cropping systems. Also the normalized volumes of the spots in the triplicates were similar for each of the plants. This is reflected by low percent standard deviations within any triplicates as well as a low number of significantly differing protein-spots between the triplicates for each vegetable. All of the selected proteins, which were differentially expressed, were excised from the gel and submitted to protein identification by MALDI tandem mass spectrometry.

\subsection{Cabbage proteome}

\subsubsection{Organic us conventional cropping}

A total of 42 protein identifications were obtained for the 58 excised cabbage protein spots that exhibited significant changes in abundance $(p \leq 0.05)$ in at least one of the organic cropping systems as compared to the conventional one, or between the two organic cropping systems $\mathrm{O} 1$ and $\mathrm{O} 2$ (Figs. 1, 2 and Table 2; details on protein spot intensity can be found in Supplementary data - Table 1). Some additional protein-spots for which the abundance varied non-significantly $(p>0.05)$, or the ratio between their expression levels was less than acceptable (see Materials and methods) but with $\mathrm{p} \leq 0.05$, were also submitted to MS/MS identification. For most of the identified proteins, the peptides generated upon tryptic digestion matched to protein sequence entries from Arabidopsis thaliana or another plant species belonging to the Brassicaceae family that also includes cabbage.
The function of the identified cabbage proteins falls into several categories within metabolism. Glycolysis and Krebs cycle were represented by 9 different proteins that were identified in 11 protein spots. Furthermore, transketolase (linking glycolysis pathway with the Calvin cycle) and truncated forms of RuBisCO were identified in 5 protein spots (number 447, $448,453,2440$ and 1294). All of these proteins were overexpressed in organically cropped vegetables, except for the Glyceraldehyde-3-phosphate dehydrogenase, (GAPDH, number 1152, see below). Expression of GAPDH was slightly suppressed in organically cropped vegetables. We also identified GAPDH in another protein-spot, the intensity of which was nearly twice as high in any of the organically cropped samples as compared to the conventional crop, but at lower significance levels ( $p=0.132$ (in 01 vs. C) and 0.054 (in O2 vs. C)). The position of these GAPDH protein-spots in the $2 \mathrm{D}$ gels suggests that the suppressed GAPDH in organically cropped samples is GAPDH B present in chloroplast, whereas the overexpressed one is GAPDH C present in the cytosol. We were unfortunately not able to distinguish between them on the basis of the sequenced peptide fragments.

Sixteen of the identified cabbage proteins related to aminoacid/protein synthesis and turnover. Five of these proteins were more abundant in samples obtained from the conventional cropping system. Of these five, three spots contained either the $\mathrm{N}$ - or C-terminus of METE_ARATH (1391, 968 and 1496), one contained a truncated polypeptide of ADP-ribosylation factor 2 (1742) and one was identified as nascent polypeptide-associated complex subunit alpha-like protein (1207). The other 11 proteinspots were overexpressed in one or both of the organically cropped vegetables as compared to the conventional crop.
A

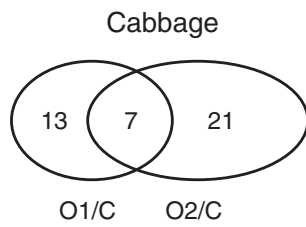

B

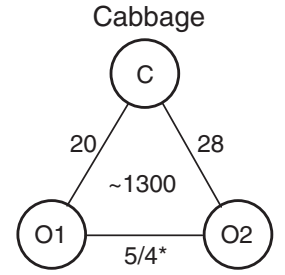

C

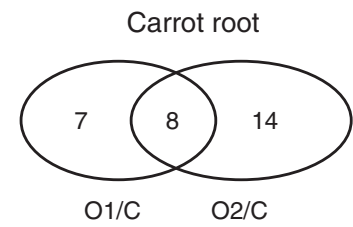

D

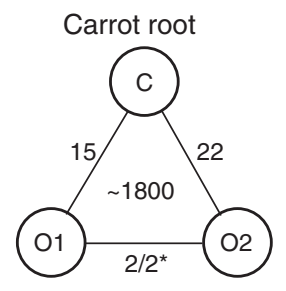

Fig. 3 - Number of differences observed between the cropping systems. A and C: number of protein-spots expression of which differed significantly between organically and conventionally cropped cabbages and carrots. B and D: number of significant differences in protein expression found in pairs of cropping systems compared. Number with asterisk indicates the number of protein-spots which expression differed not only between the organically cropped vegetables but also when any of the organic systems were compared to the conventional system. An approximate number of analyzed protein-spots is shown in the center. 
Noteworthy, truncated (475) as well as the mature forms of METE_ARATH were found in protein-spots that were more abundant in the organically cropped cabbages, although the differences in expression of the mature form was at significance levels of $p=0.053$ and 0.079 respectively (thus not included in the presented data set).

Myrosinase (609) was found to be overexpressed in organically cropped cabbages. Myrosinase catalyzes degradation of glucosinolates to either thiocyanates, isothiocyanates, nitriles, epithionitriles or oxazolidine-2-thiones. The secondary metabolites are part of the defense system of plants against insects but they also affect the flavor of the vegetable. In contrast, Annexin D1 (1677) and Glutathione S-transferase ERD13 (1514) were overproduced in conventionally cropped cabbage. Both proteins are apparently involved in detoxification processes in plant cells.

\subsection{Differences between the two organic systems as} compared to the conventional system

Twenty and 28 cabbage protein-spots were found to be differently regulated in the organic systems $\mathrm{O} 1$ or $\mathrm{O} 2$, respectively, when compared to conventional cropping system, using selection criteria as described above (Fig. 3). These two sets overlapped with 7 protein spots and for all of them, the direction of changes (up or down regulation) correlated between O1/C and O2/C. Additionally, the intensity of 5 protein spots differed significantly when comparing protein expression between the $\mathrm{O} 2$ and $\mathrm{O} 1$ systems. These proteins did not belong to one specific metabolic process.

In summary, we observed that less than $5 \%$ of all the detected and quantified cabbage protein spots exhibited significant changes in expression between any of the organic cropping systems and the conventional system. A large proportion of the identified proteins were involved in or related to glycolysis and they were up-regulated in organically grown cabbages, in both $\mathrm{O} 1$ and $\mathrm{O} 2$ systems.

\subsection{Carrot root proteome}

Only 3 of the 29 identified proteins matched directly to carrot protein sequences deposited in the sequence databases. SPITC derivatization of peptides prior to MS/MS was necessary to obtain sufficient sequence information to unambiguously identify proteins by sequence similarity searching (Supplementary data, Fig. 2). For most of the identified proteins, their molecular weight and calculated pI justified their position in the gels (Figs. 4, 5 and Table 3; details on protein spot intensity can be found in Supplementary data - Table 2). Some of the identified proteins were clearly degraded or proteolytically processed as their position on the 2D gel was deviating from the theoretical pI and Mr values.

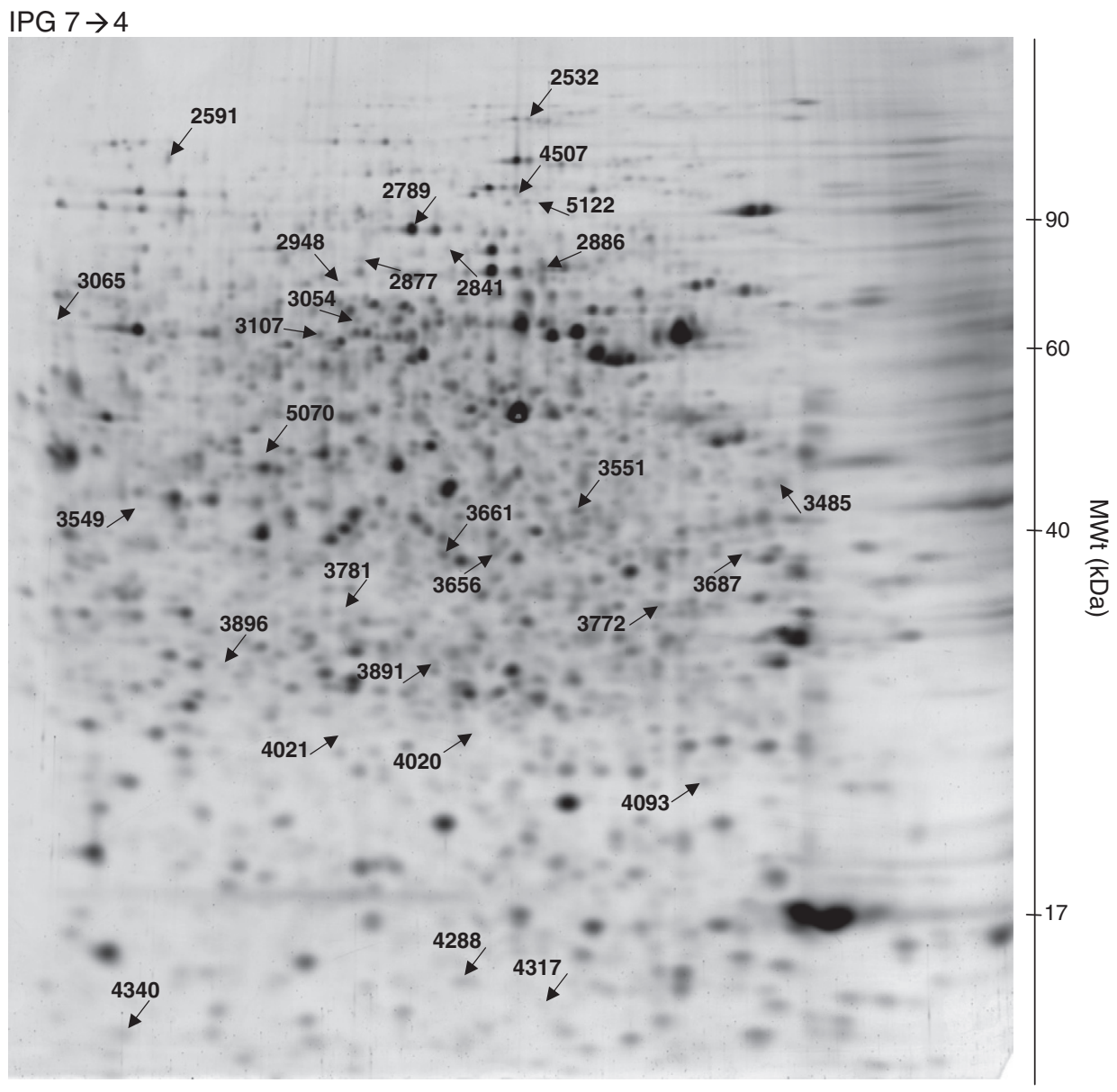

Fig. 4 - Image of the reference gel of carrot root samples. The numbers in the gel image refer to protein-spot numbers in Fig. 5 and Table 3. 


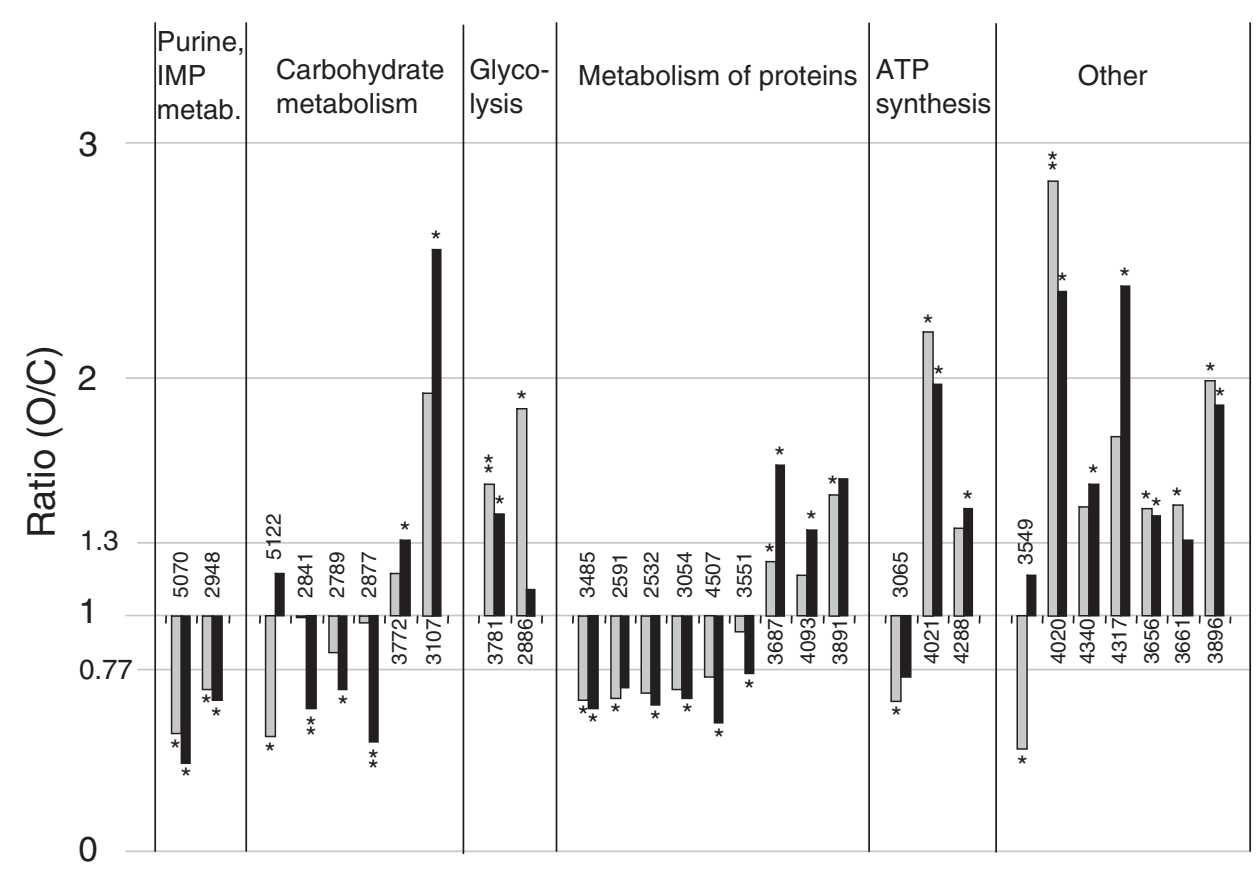

Fig. 5 - Intensity ratios for the identified proteins from differently cropped carrot roots. Ratio of spot \% volume of 01 vs $\mathrm{C}$ (gray bars) and 02 vs C (black bars). Asterisk over a bar indicates that the ratio is at probability level of $p=0.05$ or less. Bars annotated with two asterisks - additionally the ratio $02 \mathrm{vs} 01$ is significant. Numbers above or beneath a pair of bars refer to position of a protein-spot in Fig. 4 and Table 3.

\subsection{Organic us conventional cropping}

Two of the identified carrot enzymes belong in purine metabolism and IMP biosynthesis (phosphoribosylaminoimidazolesuccinocarboxamide synthase (5070) and putative phosphoribosylamino-imidazolecarboxamide formyltransferase (2948)) and were suppressed in carrots from organic systems 01 and O2. In contrast to cabbage, only two out of all the identified carrot proteins belonged to the glycolytic pathway. Both these proteins (3781 and 2886) were upregulated in carrots from organic systems. Organic cropping caused upregulation of $\mathrm{N}$ carbamoylputrescine amidase (3656), which is involved in the synthesis of polyamines. A series of metabolic processes could be identified via the functional annotation of the differentially expressed carrot proteins, however there was no consistent upor down-regulation that allowed us to make firm conclusion as to how these changes in protein expression affects the biological activity of these processes.

\subsection{Differences between the two organic systems compared to the conventional system}

Fifteen and 22 protein-spots were affected significantly by 01 and $\mathrm{O} 2$ cropping systems as compared to the Conventional system (Fig. 3). Eight protein-spots displayed significant changes in both organic systems when compared to the conventional system, and the expression ratios of these proteins correlated, i.e. they changed in the same direction in both the $\mathrm{O} 1$ and the $\mathrm{O} 2$ system.

The expression of two protein spots varied significantly between the $\mathrm{O} 1$ and $\mathrm{O} 2$ systems. These two proteins (beta-D- glucan exohydrolase-like protein (2841) and probable phosphoglucomutase 2 (2877)) are involved in carbohydrate metabolism and their expression was affected only by the $\mathrm{O} 2$ cropping system relative to the Conventional system.

\subsection{Similarities and differences between cabbage and carrot root proteomes}

Next, we compared the sets of regulated proteins that were identified in cabbage and carrot roots under various cropping regimes. Only few of the identified sets of proteins from the two different vegetable species belonged to the same protein family or functional class. ADP-ribosylation factor (1687) identified in cabbage samples and Ras-related protein Rab7 (4093) identified in carrots, belong to the GTPase superfamily of proteins involved in protein transport. In both vegetables, the organic cropping increased synthesis of these enzymes. Malic enzyme $(601,3781)$ of the glycolytic pathway was slightly, but significantly, upregulated by the organic cropping regime in both vegetables. In each of the vegetable species components of the proteasome complex $(2083,3891)$ were found to be upregulated due to organic cropping.

Transketolase like protein $(447,448)$ was identified and upregulated in organically grown (01, O2) cabbage while transketolase (2789) was identified as being down-regulated in $\mathrm{O} 2$ carrots. The BLAST similarity score for these two sequences is high, i.e. $>900$.

The organic cropping appears to have a negative effect on synthesis of proteins of carbohydrate and purine/IMP metabolism in carrot roots. In contrast to cabbage, protein metabolism appears to be negatively affected by organic cropping systems in 


\begin{tabular}{|c|c|c|c|c|c|c|c|c|c|c|c|c|}
\hline \multirow{2}{*}{$\begin{array}{l}\text { Protein } \\
\text { spot } \#^{\text {a }}\end{array}$} & \multirow[t]{2}{*}{ Acc. $\#^{\mathrm{b}}$} & \multirow[t]{2}{*}{ Protein name ${ }^{c}$} & \multirow{2}{*}{$\begin{array}{l}\text { Best } \\
\text { match to }\end{array}$} & \multicolumn{2}{|r|}{$\mathrm{O} 1 / \mathrm{C}$} & \multicolumn{2}{|r|}{$\mathrm{O} 2 / \mathrm{C}$} & \multicolumn{2}{|r|}{$\mathrm{O} 2 / \mathrm{O} 1$} & \multirow{2}{*}{$\begin{array}{c}\mathrm{m} / \mathrm{z}^{\mathrm{e}} \text { or } \\
\text { SPITC } \\
\text { derivatized } \\
\text { peptides }\end{array}$} & \multirow[t]{2}{*}{ Score ${ }^{f}$} & \multirow[t]{2}{*}{ Peptide sequence ${ }^{8}$} \\
\hline & & & & Ratio & $\begin{array}{l}\text { Probability } \\
\text { (p) }\end{array}$ & Ratio & $\begin{array}{l}\text { Probability } \\
\text { (p) }\end{array}$ & Ratio & $\begin{array}{l}\text { Probability } \\
\text { (p) }\end{array}$ & & & \\
\hline \multicolumn{13}{|c|}{ Purine metabolism; IMP biosynthesis via de novo pathway } \\
\hline 5070 & $\begin{array}{l}\text { P38025 and } \\
\text { P17784 }\end{array}$ & $\begin{array}{l}\text { Phosphoribosylaminoimidazole- } \\
\text { succinocarboxamide synthase, chloroplast } \\
\text { and Fructose-bisphosphate aldolase }\end{array}$ & $\begin{array}{l}\text { A.th.and } \\
\text { O.sa. }\end{array}$ & 0.50 & 0.0401 & 0.38 & 0.0062 & 0.76 & & $\begin{array}{l}1828.89 \\
\text { PMF }\end{array}$ & $\begin{array}{l}48 \\
58\end{array}$ & $\begin{array}{l}\text { DIYDAGDYLVLVTTDR + } \\
2 \text { matching peptides, } \\
9 \% \text { seg. coverage }\end{array}$ \\
\hline & & cytoplasmic isozyme & & & & & & & & $\begin{array}{l}1376.73 \\
\text { PMF }\end{array}$ & $\begin{array}{l}52 \\
62\end{array}$ & $\begin{array}{l}\text { VTPEVIAEYTVR + } \\
2 \text { matching peptides, } \\
8 \% \text { seq. coverage }\end{array}$ \\
\hline 2948 & Q8RWT5 & $\begin{array}{l}\text { Putative phosphoribosylamino- } \\
\text { imidazolecarboxamide formyltransferase }\end{array}$ & A.th. & 0.69 & 0.0265 & 0.65 & 0.0057 & 0.94 & & $\begin{array}{l}\text { SPITC } \\
\text { (BLASTP2) }\end{array}$ & $\begin{array}{l}83 \\
62\end{array}$ & $\begin{array}{l}\text { YGVSLLFTNVR } \\
\text { TLHPNLHG }\end{array}$ \\
\hline \multicolumn{13}{|c|}{ Carbohydrate metabolism } \\
\hline 5122 & P53535 & $\begin{array}{l}\text { Alpha-1,4 glucan phosphorylase L-2 } \\
\text { isozyme, chloroplast }\end{array}$ & S.tu. & 0.49 & 0.0068 & 1.18 & & 2.41 & & $\begin{array}{l}\text { SPITC } \\
\text { (BLASTP2) }\end{array}$ & 74 & QXXYLSFEFLQGR \\
\hline 2841 & Q9SD69 & Beta-D-glucan exohydrolase-like protein & A.th. & 0.99 & & 0.61 & 0.0006 & 0.61 & 0.0094 & $\begin{array}{l}\text { SPITC } \\
\text { (BLASTP2) }\end{array}$ & $\begin{array}{l}71 \\
31\end{array}$ & $\begin{array}{l}\text { BLTLGTTLLDAL } \\
\text { FEYPYSDR }\end{array}$ \\
\hline 2789 & Q42676 & Transketolase, chloroplast & C.pl. & 0.85 & & 0.69 & 0.0464 & 0.82 & & $\begin{array}{l}\text { SPITC } \\
\text { (BLASTP2) }\end{array}$ & $\begin{array}{l}59 \\
57 \\
54\end{array}$ & $\begin{array}{l}\text { KRPSLLALSR } \\
\text { ALGASEVDATR } \\
\text { BVTVEAASTFG }\end{array}$ \\
\hline 2877 & Q9SGC1 & $\begin{array}{l}\text { Probable phosphoglucomutase, } \\
\text { cytoplasmic } 2\end{array}$ & A.th. & 0.97 & & 0.46 & 0.0032 & 0.48 & 0.0312 & $\begin{array}{l}\text { SPITC } \\
\text { (BLASTP2) }\end{array}$ & $\begin{array}{l}109 \\
49\end{array}$ & $\begin{array}{l}\text { BIYIEQYEKDSSKLGR } \\
\text { BSLFDFQS }\end{array}$ \\
\hline 3772 & Q84XU3 & Putative 6-phosphogluconolactonase & E.gu. & 1.18 & & 1.32 & 0.0336 & 1.12 & & $\begin{array}{l}\text { SPITC } \\
\text { (BLASTP2) }\end{array}$ & $\begin{array}{l}69 \\
37\end{array}$ & $\begin{array}{l}\text { GAFTLVLSGGDL } \\
\text { YLAELSD }\end{array}$ \\
\hline 3107 & Q9SU63 & $\begin{array}{l}\text { Aldehyde dehydrogenase 2B4, } \\
\text { mitochondrial }\end{array}$ & A.th. & 1.94 & & 2.55 & 0.0120 & 1.31 & & $\begin{array}{l}\text { SPITC } \\
\text { (BLASTP2) }\end{array}$ & $\begin{array}{l}76 \\
44\end{array}$ & $\begin{array}{l}\text { GLYSLNNYLQ } \\
\text { YQDVNEVLQR }\end{array}$ \\
\hline \multicolumn{13}{|c|}{ Glycolysis } \\
\hline 3781 & P37225 & $\begin{array}{l}\text { NAD-dependent malic enzyme } 59 \mathrm{kDa} \\
\text { isoform, mitochondrial, C-terminus }\end{array}$ & S.tu. & 1.55 & 0.0038 & 1.43 & 0.0082 & 0.92 & 0.0323 & $\begin{array}{l}\text { SPITC } \\
\text { (BLASTP2) }\end{array}$ & $\begin{array}{l}76 \\
44\end{array}$ & $\begin{array}{l}\text { DLTAEVAAAVLR } \\
\text { PALFAFSN }\end{array}$ \\
\hline 2886 & Q9M9K1 & $\begin{array}{l}\text { Probable 2,3-bisphosphoglycerate-independent } \\
\text { phosphoglycerate mutase } 2\end{array}$ & A.th. & 1.87 & 0.0190 & 1.11 & & 0.59 & & 1776.93 & 52 & AVGPIVDGDAVVTFNFR \\
\hline \multicolumn{13}{|c|}{ Metabolism of proteins } \\
\hline 3485 & Q9XJ56 & Phosphoprotein ECPP44 & D.ca. & 0.65 & 0.0070 & 0.61 & 0.0103 & 0.94 & & $\begin{array}{l}811.43 \\
873.40 \\
1001.49 \\
1065.52\end{array}$ & $\begin{array}{l}27 \\
35 \\
44 \\
68\end{array}$ & $\begin{array}{l}\text { IPGYHPK } \\
\text { GLFDFMK (Mox) } \\
\text { GLFDFMKK (Mox) } \\
\text { VIATEFEEK }\end{array}$ \\
\hline 2591 & $\mathrm{O} 23755$ & Elongation factor 2 & B.vu. & 0.65 & 0.0406 & 0.70 & & 1.07 & & PMF & 59 & $\begin{array}{l}7 \text { matching peptides, } \\
9 \% \text { seq. coverage }\end{array}$ \\
\hline 2532 & Q8VZ83 & Putative heat-shock protein & A.th. & 0.67 & & 0.63 & 0.0084 & 0.93 & & $\begin{array}{l}\text { SPITC } \\
\text { (BLASTP2) }\end{array}$ & 75 & LLTEFFGQEPR \\
\hline 3054 & Q6AV23 & $\begin{array}{l}\text { Putative TCP-1/cpn } 60 \text { chaperonin } \\
\text { family protein }\end{array}$ & O.sa. & 0.69 & & 0.65 & 0.0473 & 0.95 & & $\begin{array}{l}\text { SPITC } \\
\text { (BLASTP2) }\end{array}$ & 87 & BQGLLLSATEAAEFLLR \\
\hline 4507 & Q87JT1 & Putative protease & V.pa. & 0.74 & & 0.55 & 0.0290 & 0.74 & & $\begin{array}{l}\text { SPITC } \\
\text { (BLASTP2) }\end{array}$ & 75 & GFVFALAHLR \\
\hline 3551 & gi|15225613 & $\begin{array}{l}\text { 60S acidic ribosomal protein P0 } \\
\text { (RPPOA) }\end{array}$ & A.th. & 0.93 & & 0.76 & 0.0007 & 0.81 & & $\begin{array}{l}1411.83 \\
1767.05\end{array}$ & $\begin{array}{l}97 \\
95\end{array}$ & $\begin{array}{l}\text { GTVEIITPVELIK } \\
\text { INKGTVEIITPVELIK }\end{array}$ \\
\hline
\end{tabular}




C

Ratio

\begin{tabular}{|c|c|c|c|c|c|c|c|c|c|c|c|c|}
\hline \multicolumn{13}{|c|}{ Metabolism of proteins } \\
\hline 3687 & 004204 & 60 acidic ribosomal protein $\mathrm{P} 0-1$ & A.th. & 1.23 & 0.0268 & 1.64 & 0.0147 & 1.33 & & 1411.83 & 91 & GTVEIITPVELIK \\
\hline \multirow[t]{2}{*}{4093} & Q9XER8 & Ras-related protein Rab7 & G.hi. & 1.17 & & 1.36 & 0.0191 & 1.16 & & 1187.60 & 57 & FQSLGVAFYR \\
\hline & & & & & & & & & & 1226.58 & 72 & GNIPYFETSAK \\
\hline 3891 & O23708 & Proteasome subunit alpha type-2-A & A.th. & 1.51 & 0.0253 & 1.58 & & 1.05 & & $\begin{array}{l}\text { SPITC } \\
\text { (BLASTP2) }\end{array}$ & 105 & LQLLTPNLGVVYSGFGPDSR \\
\hline \multicolumn{13}{|c|}{ ATP synthesis } \\
\hline \multirow[t]{2}{*}{3065} & Q06735 & $\begin{array}{l}\text { ATP synthase subunit alpha, } \\
\text { mitochondrial }\end{array}$ & B.vu. & 0.64 & 0.0202 & 0.74 & & 1.16 & & $\begin{array}{l}1210.68 \\
1537.74\end{array}$ & $\begin{array}{l}56 \\
60\end{array}$ & $\begin{array}{l}\text { VVDALGVPIDGR } \\
\text { EAFPGDVFLHSR }\end{array}$ \\
\hline & & & & & & & & & & 2308.16 & 81 & EVAAFAQFGSDLDAATQALLNR \\
\hline 4021 & Q94N42 & $\begin{array}{l}\text { ATP synthase subunit alpha } \\
\text { (truncated) }\end{array}$ & D.ca. & 2.20 & 0.0030 & 1.98 & 0.0187 & 0.90 & & $\begin{array}{l}\text { SPITC } \\
\text { (BLASTP2) }\end{array}$ & $\begin{array}{l}137 \\
40\end{array}$ & $\begin{array}{l}\text { EVAAFAEFGSDLDAATQALLNR } \\
\text { VLTSLLL }\end{array}$ \\
\hline 4288 & Q6KAA4 & $\begin{array}{l}\text { Putative Vacuolar ATP synthase } \\
\text { subunit F }\end{array}$ & O.sa. & 1.37 & & 1.45 & 0.0033 & 1.06 & & $\begin{array}{l}\text { SPITC } \\
\text { (BLASTP2) }\end{array}$ & $\begin{array}{l}84 \\
77\end{array}$ & $\begin{array}{l}\text { LALVLVSQYVANFLR } \\
\text { QLEDAFQEFTAR }\end{array}$ \\
\hline \multicolumn{13}{|l|}{ Other } \\
\hline \multirow[t]{2}{*}{3549} & P35055 & $\begin{array}{l}\text { Coproporphyrinogen III oxidase, } \\
\text { chloroplast }\end{array}$ & G.ma. & 0.44 & 0.0160 & 1.17 & & 2.66 & & $\begin{array}{l}\text { SPITC } \\
\text { (BLASTP2) }\end{array}$ & 86 & $\begin{array}{l}\text { LESLLVSLPLTAR } \\
\text { YVEFNLVYDR }\end{array}$ \\
\hline & & & & & & & & & & & 83 & NXXAPTLHFNYR \\
\hline 4020 & Q8GRA4 & Catalase (truncated) & P.gu. & 2.84 & 0.0017 & 2.37 & 0.0058 & 0.83 & 0.0180 & $\begin{array}{l}\text { SPITC } \\
\text { (BLASTP2) }\end{array}$ & $\begin{array}{l}66 \\
34\end{array}$ & $\begin{array}{l}\text { LFAYGDTQR } \\
\text { YFGQPR }\end{array}$ \\
\hline 4340 & P47919 & Nucleoside diphosphate kinase A & F.bi. & 1.46 & & 1.56 & 0.0080 & 1.07 & & $\begin{array}{l}\text { SPITC } \\
\text { (BLASTP2) }\end{array}$ & 83 & TNPAESAPGTLR \\
\hline 4317 & Q762A0 & Nucleoside diphosphate kinase & O.sa. & 1.76 & & 2.39 & 0.0113 & 1.36 & & $\begin{array}{l}\text { SPITC } \\
\text { (BLASTP2) }\end{array}$ & 105 & LLGSTNPLQAEPGTLR \\
\hline 3656 & Q8VYF5 & $\mathrm{N}$-carbamoylputrescine amidase & A.th. & 1.45 & 0.0385 & 1.42 & 0.0211 & 0.98 & & $\begin{array}{l}\text { SPITC } \\
\text { (BLASTP2) }\end{array}$ & $\begin{array}{l}97 \\
63\end{array}$ & $\begin{array}{l}\text { HAGANVVPLVASNR } \\
\text { BFYFNPGD }\end{array}$ \\
\hline \multirow[t]{4}{*}{3661} & Q9FT36 & Tubulin alpha chain (C-truncated) & D.ca. & 1.47 & 0.0115 & 1.32 & & 0.90 & & 1473.85 & 42 & LVSQVISSLTASLR \\
\hline & & & & & & & & & & 1691.86 & 51 & SLDIERPTYTNLNR \\
\hline & & & & & & & & & & 1715.91 & 108 & AIFVDLEPTVIDEVR \\
\hline & & & & & & & & & & 1977.87 & 157 & TVGGGDDAFNTFFSETGAGK \\
\hline \multirow[t]{2}{*}{3896} & 048587 & Dreg-2 like protein & A.th. & 1.99 & 0.0227 & 1.89 & 0.0111 & 0.95 & & SPITC & 90 & GLIVGLVSNAEYR \\
\hline & & & & & & & & & & (BLASTP2) & 41 & HALLLDR \\
\hline
\end{tabular}

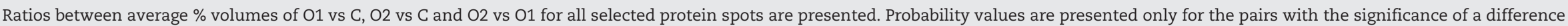
equal or below 0.05 . All the identified peptides were "1+" charged. Sequences obtained after SPITC derivatization of peptides were searched against nrdb95 using BLASTP2 search engine at EMBL.

a Protein spot \# as in Figs. 4 and 5.

b Acc \# - protein accession number derived from either SwissProt or NCBI nonredundant databases.

c Protein name derived from either SwissProt or NCBI nonredundant databases.

d An organism is presented, protein of which is the best mach for the deduced (by means of MS/MS) amino acid sequence of peptide(s) from proteins analyzed in this work, abbreviations: A.th. -

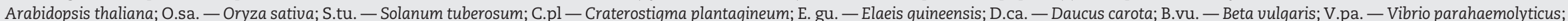
G.hi. - Gossypium hirsutum; G.ma. - Glycine max; P.gu. - Porphyromonas gulae; F.bi. — Flaveria bidentis.

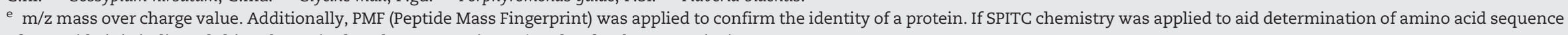
of a peptide it is indicated this column (rather than presenting $\mathrm{m} / \mathrm{z}$ value for the parent ion).

${ }^{f}$ Score: mascot score is presented for the identified peptides by MSMS at $\mathrm{p}<0.05$. If PMF is present, the score concerns the identified protein at $\mathrm{p}<0.05$.

8 Mox - oxidized methionine. 
carrot roots as a number of chaperones and proteins of protein synthesis machinery were found down regulated in carrot root samples but not in cabbages.

\section{Discussion}

We present results from proteome analysis of cabbage and carrot grown under conventional and two organic cropping regimes obtained in the 2 nd of the 4 -year project. The samples were obtained from fresh plant material and proteins were extracted using an optimized extraction protocol. The two extraction methods that we initially tested allow for preparation of protein samples suitable for 2D electrophoretic separation from carrots and cabbages. Using these methods postharvest proteolysis and chemical modification of proteins is apparently inhibited or very limited, which is reflected by high reproducibility of patterns and abundance of separated proteins between samples. There are however significant qualitative and quantitative differences between protein patterns obtained using the two different methods. Within the VegQure project we investigate also the interaction, on a protein expression level (by means of 2DE), between pathogenic fungus $M$. acerina and carrot root. We were not able to extract proteins, in sufficient amounts, from pure cultures of the fungus using the method employing TCA/beta-mercaptoethanol/acetone precipitation. Extraction of these proteins was facilitated by employing the method of ethanol/acetone precipitation. We therefore used the latter method in all subsequent analysis.

The patterns of 2DE separated proteins were very similar for each of the vegetables across the three cropping systems, and we detected significant quantitative differences in only 58 of 1300 proteins in cabbage and in 68 of 1800 proteins in carrot roots. This result was obtained based on a low average standard deviation of the protein-spot intensity among the three replicate samples from the field. This allowed us to identify even moderate changes in protein expression of only $30 \%$ due to different treatments of the crops in the field. This low variability shows that the field variation was low which is of course a pre-requisite for being able to measure treatment effects, but also that the sampling and extraction protocols we developed kept sampling error at a low level.

The low variability allowed us to measure differences among crops which were almost identical as judged by visual inspection, complementary analytical techniques and sensory tests. Vegetable yield and $\mathrm{N}$ content were only slightly reduced in the two organic systems compared to the conventional systems, and the dry matter content of the vegetables was not affected at all. This is quite different from the results of another study [8] where the $\mathrm{N}$ content, the yield and dry matter content were all significantly affected, and where the $\mathrm{N}$ content was $50 \%$ higher in conventional potatoes compared to organically grown potatoes. As crop $\mathrm{N}$ content is very closely related to crop protein content, it is obvious that changes in $\mathrm{N}$ content must be reflected in quantitative changes in the content of some proteins. In the present study we were able to show clear effects of cropping methods even though the product quality was apparently affected very little.

In study of Lehesranta and coworkers [8], it was found that fertility management practices (organic matter vs. mineral fertilizer based) caused quantitative difference in approx. 15\% of the potato tuber proteome. This is clearly higher than the approx. 5\% differentially expressed proteins observed in our study of cabbage and carrot. This difference may be explained by larger differences in crop yield especially in $\mathrm{N}$ content between the organic and conventional crops in their study [8].

Protein synthesis and turnover, carbon and energy metabolism as well as defense responses were found to be positively affected by organic fertilization of potatoes [8] and the authors suggest that organic fertilization leads to an increased stress response in potato tubers. Our results are in agreement with these observations especially as far as the cabbage proteome is concerned. In particular, we also found proteins related to glycolysis, amino acid and protein metabolism being overexpressed in cabbages grown under any of the organic cropping regimes.

The similarity in proteome changes as seen between cabbage and potato tubers was less clear between the carrots and cabbages. Additional metabolic processes were affected by different cropping schemes of carrots, but still several proteins were affected similarly in the two crops. Fewer proteins were affected by the cropping scheme in carrot roots as compared to cabbage (relative to the total number of all quantified protein-spots in the vegetables), but that may be related to the very low difference in growth and yield of the carrots in the cropping systems.

The samples collected for cabbage and carrot root span different plant organs and comprise different metabolizing tissues of plants. Samples from cabbage contain proteins from photosynthetic tissues, and specialized storage and transport organs (stem). Protein samples of carrot root are obtained from root cells responsible mainly for storage and transport of water and metabolites. The parts of the plants taken for protein sampling are also exposed to different environments, i.e. light and air for cabbage and darkness, soil, and abundant soil microorganisms for carrots. Therefore, observation of differential effects on proteins involved in metabolic processes in response to the same cropping regime between these two vegetables is not surprising. On the other hand, the similarities found in response to the same cropping regime in both vegetables might be the true indicators of the effects of the various cropping systems.

We identified a number of proteins which differed significantly in expression between conventional and organic production, but we also found that specific functional groups of proteins were affected in the same way, e.g. enzymes involved in the glycolytic pathway were upregulated in both organic systems as compared to the conventional cropping systems in both cabbages and carrots. All in all, the number of proteins which differed significantly between the conventional scheme and either of the two organic cropping systems was approx. 7 and 4 times higher (cabbage and carrot, respectively) than the number of proteins which deviated significantly between the two organic systems. These results show that proteomic analysis allowed us to measure not only "scattered up- and down-regulation of a few proteins" but to identify important and general effects of the cropping systems on plant metabolism. Such results also indicate why studies of how organic cropping methods affect product quality often lead to inconclusive results. If we had chosen to study only a 
few selected proteins, rather than the 1300 and 1800 studied here for cabbage and carrot respectively, the likelihood that we found any significant effects would be very low. If we found anything significant it could show increased or decreased protein expression in the organic systems almost at random. This is a likely reason for the often inconclusive results from studies of effects on secondary compounds in plants (e.g. [32]), and shows the strength of a broad range method as proteomic analysis.

The subjects and focus of our investigations was the protein metabolism in the mature crops. As showed by Zörb and co-workers [33], a higher number of metabolic differences, caused by organic and conventional cropping regimes were detected during developmental stages of grains rather than in mature grains. Therefore we are aware, that had the subject for our investigations been effect of cropping systems on plants metabolism during their development, we might have observed a larger number or a different set of metabolic changes.

In conclusion, we have demonstrated that it is possible to use proteome analysis to reveal differential expression of specific proteins in plant tissues, even among plant material differing very little in other respects. Using MS/MS we were able to sequence peptides and identify proteins in cabbage and carrot despite the absence of completed genome sequences for these species. We also showed that protein abundance as well as plant metabolism is affected by different cropping regimes, and that there are some general effects of the two organic cropping methods $\mathrm{O} 1$ and $\mathrm{O} 2$ as compared to the conventional production system. We predict that proteome analysis will play an increasingly important role in monitoring the quality of edible plants and other types of human food and in optimization of farming methods for a variety of agricultural products.

Supplementary materials related to this article can be found online at doi:10.1016/j.jprot.2011.06.021.

\section{Acknowledgment}

We thank Jørgen Villebro and Knud Erik Pedersen for the collaboration in field work and Birthe Riis Flyger for her excellent assistance during sample collection and preparation. We thank Andrea Maria Lorentzen for mass spectrometry support. This project was supported by a FØJO grant 'VegQure' to K.T.K (no. 3304-FOJO-05-45-07). Research in the O.N.J. laboratory is supported by the Lundbeck Foundation and the Danish Research Agency. Mass spectrometry instrumentation was co-financed by the University of Southern Denmark.

\section{R E F E R E N C E S}

[1] Williams CM. Nutritional quality of organic food: shades of grey or shades of green? Proc Nutr Soc 2002;61:19-24.

[2] Stamp N. Out of the quagmire of plant defense hypotheses. Q Rev Biol 2003;78:23-55.

[3] Sainju UM, Whitehead WF, Singh BP. Agricultural management practices to sustain crop yields and improve soil and environmental qualities. Scientific World Journal 2003;3: 768-89.

[4] Thorup-Kristensen K. Root growth and nitrogen uptake by carrot early cabbage onion and lettuce following a range of green manures. Soil Use Manage 2006;22:29-38.

[5] Thorup-Kristensen K, Magid J, Jensen JS. Catch crops and green manures as biological tools in nitrogen management in temperature zones. Adv Argon 2003;79:227-301.

[6] Young JE, Zhao X, Carey EE, Welti R, Yang SS, Wang W. Phytochemical phenolics in organically grown vegetables. Mol Nutr Food Res 2005;49:1136-42.

[7] Vian MA, Tomao V, Coulomb PO, Lacombe JM, Dangles O. Comparison of the anthocyanin composition during ripening of Syrah grapes grown using organic or conventional agricultural practices. J Agric Food Chem 2006;54:5230-5.

[8] Lehesranta SJ, Koistinen KM, Massat N, Davies HV, Shepherd LV, McNicol JW. Effects of agricultural production systems and their components on protein profiles of potato tubers. Proteomics 2007;7:597-604.

[9] Weiss W, Görg A. Two-dimensional electrophoresis for plant proteomics. Methods Mol Biol 2007;355:121-43.

[10] Lehesranta SJ, Davies HV, Shepherd LV, Nunan N, McNicol JW, Auriola S. Comparison of tuber proteomes of potato varieties landraces and genetically modified lines. Plant Physiol 2005;138:1690-9.

[11] Albertin W, Brabant P, Catrice O, Eber F, Jenczewski E, Chèvre AM. Autopolyploidy in cabbage (Brassica oleracea L) does not alter significantly the proteomes of green tissues. Proteomics 2005;5:2131-9.

[12] Dodeman VL, Le Guilloux M, Ducreux G, de Vienne D. Somatic and zygotic embryos of Daucus carota L display different protein patterns until conversion to plants. Plant Cell Physiol 1998;39:1104-10.

[13] Sánchez-Morán E, Mercier R, Higgins JD, Armstrong SJ, Jones $\mathrm{GH}$, Franklin FC. A strategy to investigate the plant meiotic proteome. Cytogenet Genome Res 2005;109:181-9.

[14] Hjernø K, Alm R, Canbäck B, Matthiesen R, Trajkovski K, Björk L. Down-regulation of the strawberry Bet $v$ 1-homologous allergen in concert with the flavonoid biosynthesis pathway in colorless strawberry mutant. Proteomics 2006;6:1574-87.

[15] Peck SC, Nühse TS, Hess D, Iglesias A, Meins F, Boller T. Directed proteomics identifies a plant-specific protein rapidly phosphorylated in response to bacterial and fungal elicitors. Plant Cell 2001;13:1467-75.

[16] Ayele M, Haas BJ, Kumar N, Wu H, Xiao Y, Van Aken S. Whole genome shotgun sequencing of Brassica oleracea and its application to gene discovery and annotation in Arabidopsis. Genome Res 2005;15:487-95.

[17] Ruhlman T, Lee SB, Jansen RK, Hostetler JB, Tallon LJ, Town CD. Complete plastid genome sequence of Daucus carota: implications for biotechnology and phylogeny of angiosperms. BMC Genomics 2006;7:222.

[18] The Arabidopsis Genome Initiative. Analysis of the genome sequence of the flowering plant Arabidopsis thaliana. Nature 2000;408:796-815.

[19] Koistinen KM, Hassinen VH, Gynther PAM, Lehesranta SJ, Keinänen SI, Kokko HI. Birch PR-10c is induced by factors causing oxidative stress but appears not to confer tolerance to these agents. New Physiol 2002;155:381-91.

[20] Méchin V, Damerval C, Zivy M. Total protein extraction with TCA-acetone. Methods Mol Biol 2007;355:1-8.

[21] Watson BS, Sumner LW. Isolation of cell wall proteins from Medicato sativa stems. Methods Mol Biol 2007;355:79-92.

[22] Faurobert M, Pelpoir E, Chaib J. Phenol extraction of proteins for proteomic studies of recalcitrant plant tissues. Methods Mol Biol 2007;355:9-14.

[23] Roth KD, Huang ZH, Sadagopan N, Watson JT. Charge derivatization of peptides for analysis by mass spectrometry. Mass Spectrom Rev 1998;17:255-74. 
[24] Keough T, Youngquist RS, Lacey MP. A method for high-sensitivity peptide sequencing using postsource decay matrix-assisted laser desorption ionization mass spectrometry. Proc Natl Acad Sci USA 1999;96:7131-6.

[25] Marekov LN, Steinert PM. Charge derivatization by 4-sulfophenyl isothiocyanate enhances peptide sequencing by post-source decay matrix-assisted laser desorption/ionization time-of-flight mass spectrometry. J Mass Spectrom 2003;38:373-7.

[26] Shevchenko A, Sunyaev S, Loboda A, Shevchenko A, Bork P, Ens $\mathrm{W}$. Charting the proteomes of organisms with unsequenced genomes by MALDI-quadrupole time-of-flight mass spectrometry and BLAST homology searching. Anal Chem 2001;73:1917-26.

[27] Agrawal GK, Thelen JJ. Large scale identification and quantitative profiling of phosphoproteins expressed during seed filling in oilseed rape. Cell Proteomics 2006;5:2044-59.

[28] Nawrocki A, Fey SJ, Goffeau A, Roepstorff P, Larsen PM. The effects of transcription regulating genes PDR1 pdr1-3 and PDR3 in pleiotropic drug resistance. Proteomics 2001;1: 1022-32 Erratum in: Proteomics 2001;1:1340-1.
[29] Shevchenko A, Wilm M, Vorm O, Mann M. Mass spectrometric sequencing of proteins silver-stained polyacrylamide gels. Anal Chem 1996;68:850-8.

[30] Jensen ON, Larsen MR, Roepstorff P. Mass spectrometric identification and microcharacterization of proteins from electrophoretic gels: strategies and applications. Proteins Struct Funct Genet 1998;33(S2):74-89.

[31] Gobom J, Nordhoff E, Mirgorodskaya E, Ekman R, Roepstorff P. Sample purification and preparation technique based on nano-scale reversed-phase columns for the sensitive analysis of complex peptide mixtures by matrix-assisted laser desorption/ionization mass spectrometry. J Mass Spectrom 1999;34:105-16.

[32] Brandt K, Mølgaard JP. Organic agriculture: does it enhance or reduce the nutritional value of plant foods? Sci Food Agric 2001;81:924-31.

[33] Zörb C, Niehaus K, Barsch A, Betsche T, Langenkämper G. Levels of compounds and metabolites in wheat ears and grains in organic and conventional agriculture. J Agric Food Chem 2009;57:9555-62. 